\title{
MODEL PREDIKSI KELULUSAN TEPAT WAKTU DENGAN METODE FUZZY C-MEANS DAN K-NEAREST NEIGHBORS MENGGUNAKAN DATA REGISTRASI MAHASISWA
}

\author{
Silvana Puspa Nabila ${ }^{1)}$, Nurissaidah Ulinnuha ${ }^{2)}$, Ahmad Yusuf ${ }^{3)}$ \\ 1), 3) Sistem Informasi, Fakultas Sains dan Teknologi, UIN Sunan Ampel, Surabaya \\ ${ }^{2)}$ Matematika, Fakultas Sains dan Teknologi, UIN Sunan Ampel, Surabaya \\ Jl. Ahmad Yani No.117, Jemur Wonosari, Surabaya, Jawa Timur \\ Email:silvana.puspa01@gmail.com ${ }^{1)}$,nuris.ulinnuha@uinsby.ac.id ${ }^{2}$, ahmadyusuf@uinsby.ac.id ${ }^{3}$. \\ Corresponding author. Phone : +6289677134932
}

\begin{abstract}
Abstrak
Kegiatan Penerimaan Mahasiswa Baru di tingkat perguruan tinggi setiap tahunnya merupakan suatu kegiatan yang wajib dilaksanakan untuk membuka awal tahun ajaran baru, salah satunya yakni di kampus Universitas Islam Negeri Sunan Ampel Surabaya (UINSA). Namun permasalahannya yakni, tidak semua mahasiswa dapatlulus secara tepat waktu sesuai dengan waktu tempuh kurikulum yang telah disusun, hal ini akan berpengaruh pada akreditasi perguruan tinggi. Untuk meminimalisir hal tersebut maka, pada penelitian ini akan diusulkan model prediksi dengan teknik data mining dan machine learning guna membantu memperbaiki konsep registrasi pada mahasiswa baru. Yakni dengan membuat model prediksi menggunakan metode FCM-KNN, konsep metode ini adalah pada tahap pengelompokkan dan pemberian label data digunakan FCM kemudian pada tahap penentuanjarak antar data digunakan KNN dengan hal tersebut makajarak antara k-tetangga terdekat cukup dicari pada lingkup anggota kelompok data dalam satu cluster dan tidak perlu dibandingkan oleh data keseluruhan. Pada penelitian ini menggunakan data registrasi mahasiswa UINSA, kemudian pengujian skor akan digunakan confusion matrix dank-fold cross validation. Hasil dari algoritma FCM-KNN didapatkan bahwa model prediksi dengan pengujian 10-fold cross validation dengan skenario $k=1$ mempunyai rata rata akurasi sebesar $71 \%$ kesimpulannya dengan seiring bertambahnyanilai K(tetangga terdekat) maka akan mempengaruhi nilai akurasi.
\end{abstract}

Kata kunci: Confusion Matrix, FCM-KNN, K-fold, Machine Learning, Penerimaan Mahasiswa Baru.

\begin{abstract}
The new student admission activity at the tertiary level is an activity that must be carried out everyyear to open the beginning of a new academic year, one of which is on the campus of the Sunan Ampel State Islamic University Surabaya (UINSA). However, the problem is, not all students can graduate on time according to the time taken for the curriculum that has been prepared, this will affect the accreditation of higher education. To minimize this, this research proposes a prediction model using data mining and machine learning techniques to help improve the concept of registration for new students. Namely by making a prediction model using the FCM-KNN method, the concept of this method is that at the stage of grouping and labeling the data used FCM then at the stage of determining the distance between the data used KNN with this, the distance between the k-closest neighbors is enough to look for within the scope of the data group members. In one cluster and need not be compared by the whole data. In this study using UINSA student registration data, then score testing will use confusion matrix and $k$-fold cross validation. The results of the FCM-KNN algorithm show that the prediction model by testing 10-fold cross validation with the $k=1$ scenario has an average accuracy of $71 \%$.
\end{abstract}

Keywords: Confusion Matrix, FCM-KNN, Graduate on time, K-fold, Machinelearning.

\section{PENDAHULUAN}

Peningkatan jumlah pendaftar di perguruan tinggi Indonesia baik negeri maupun swasta dari waktu ke waktu mengalami peningkatan yang cukup banyak. Hal ini juga harus diimbangi dengan cara seleksi penerimaan mahasiswa agar dapat memperoleh calon mahasiswa baru yang berkualitas. Salah satu ciri mahasiswa yang berkualitas bukan hanya yang memiliki tingkat intelektual yang tinggi, namun juga dapat menyelesaikan masa studi pendidikan dengan baik [1].

Pada saat ini, permasalahan yang ada adalah pihak UINSA masih menggunakan seleksi manual untuk dapat mengetahui karakteristik mahasiswa yang berpotensial kemungkinan lulus secara tepat waktu. Hal ini cukup penting untuk membantu UINSA dalam mengambil sebuah 
keputusan untuk menyeleksi mahasiswa baru. Oleh karena itu, penelitian ini akan menggunakan teknik data mining dan machine learning untuk membuat model prediksi. Definisi data mining adalah sebuah teknik dalam statistik, matematika, artificial intelligence, dan machine learning yang berguna untuk mengekstrasi dan mengidentifikasi suatu informasi baru yang berguna dari suatu pengetahuan mengenai berbagai database [2]. sedangkan definisi machine learning yaitu membuat model secara matematis yang menggambarkan pola suatu data [3]. Banyak sekali algoritma machine learning yang dapat diterapkan, beberapa algoritma populer yang biasa digunakan dalam prediksi yaitu K-Nearest Neighbors, Decision Tree, K-Means. Namun pada penelitian ini akan digunakan algoritma penggabungan antara FCM dan KNN.

Konsep dari metode FCM-KNN ini adalah dengan mengelompokkan data yang serupa terlebih dahulu sebelum dilakukan pemberian label. Pada tahap ini, pemberian label cluster digunakan algoritma FCM dan kemudian penentuan kelas digunakan algoritma KNN. Karena dengan adanya pengelompokan data terlebih dahulu, maka diharapkan dapat meningkatkan performa kategorisasi serta dapat menghemat waktu komputasi dalam memilih k-tetangga terdekat. Karena dengan hal tersebut jarak antar k cukup diperoleh dengan lingkup anggota kelompok dalam satu cluster saja dan tidak perlu dibandingkan oleh data keseluruhan [4].

Tentunya penelitian ini bukanlah penelitian yang pertama kalinya, karena sudah banyak jurnal yang telah membahas topik ini. Pada penelitian sebelumnya mengenai prediksi menggunakan data nilai mahasiswa juga dilakukan oleh [5]. Pada penelitian tersebut menggunakan nilai mahasiswa sebagai parameternya. Dari data nilai mahasiswa tersebut akan di cluster menjadi beberapa kelompok yang telah sesuai dengan parameter jumlah cluster (k) yang sudah ditetapkan, dari hasil clustering tersebut maka akan keluar hasil k-cluster data nilai mahasiswa. Hasil dari metode ini cukup baik terlihat dari nilai kesalahan RMSE sekitar 0.05-0.08 dari dataset yang digunakan.

Pada penelitian yang dilakukan oleh [6] dengan menggunakan teknik data mining menyatakan bahwa kinerja program akademik merupakan salah satu faktor yang paling penting dalam mempengaruhi suatu kualitas pendidikan yang lebih tinggi. Penelitian ini menggunakan algoritma Naive baiyes dan mendapatkan model dengan akurasi $91 \%$ untuk memprediksi kegagalan mahasiswa dalam mata kuliah. Selanjutnya, Penelitian ini merupakan pengembangan metode dari penelitian sebelumnya yang dilakukan oleh [4] yang juga menggunakan konsep algoritma FCM-KNN namun perbedaan nya terletak pada data yang digunakan, penelitian tersebut melakukan percobaan k-1 hingga k-10. Didapatkan k-1 adalah yang terbaik dan mendapatkan skor F1 sebesar 93,33\% dari 18 dokumen terklasifikasi dengan benar dan 2 tidak terklasifikasi. Kemudian ada juga penelitian dari [7] yang membahas mengenai Penerapan Koptimal pada Algoritma KNN Untuk Prediksi Kelulusan Tepat Waktu Mahasiswa menghasilkan k-5 sebagai k tetangga terdekat terbaik dengan hasil pengujian $K$-Fold Cross Validation didapatkan tingkat akurasi untuk $\mathrm{K}=5$ sebesar $80,00 \%$.

\section{DASAR TEORI}

\subsection{Data Mining}

Data mining bukanlah suatu hal baru di bidang ilmu komputer dan dunia data. Maka dari itu, tujuan data mining yakni untuk memperbaiki suatu teknik atau cara tradisional sehingga dapat menangani dimensi data yang tinggi, juga jumlah data yang sangat besar dan data yang berbeda sifat dan heterogen [8]. Dalam pengelompokan data mining akan dibagi menjadi enam kelompok yaitu Deskripsi, Estimasi, Prediksi, Klasifikasi, Klaster dan Asosiasi [8]. Sedangkan untuk tahap pembentukan model data mining dibagi menjadi dua yakni data testing dan data training. Pada data training, data yang telah diketahui kelompoknya akan melatih model dengan menggunakan teknik algoritma tertentu. Setelah tahap sebelumnya selesai maka selanjutnya tahap testing atau tahap uji coba berguna untuk menguji nilai akurasi daripada model tersebut [9].

\subsection{Metode Pembelajaran Model}

Metode pembelajaran model memiliki dua kategori yaitu Pembelajaran terawasi (Supervised Learning) dan Pembelajaran tak terawasi (Unsupervised Learning). Pada teknik supervised learning proses awalnya memerlukan beberapa data training dan data yang telah ditentukan kelas dan kelompok sebelumnya atau yang biasa disebut label dan keluarannya telah diketahui [10]. Yang termasuk supervised learning diantaranya klasifikasi, regresi, dan prediksi. 
Sedangkan pada teknik unsupervised learning ini, sebuah struktur kelompok data berdasarkan suatu pola tertentu yang belum ditentukan sebelumnya dan belum terdapat output yang diperoleh [11]. Perbedaan dari pembelajaran supervised learning yaitu data training tidak perlu diberikan label.

\section{$2.3 \quad$ K-Nearest Neighbors}

Algoritma KNN merupakan suatu algoritma klasifikasi dan termasuk ke dalam algoritma supervised learning. Algoritma ini menggunakan klasifikasi terhadap suatu objek berdasarkan data jarak tetangga (neighbor) terdekatnya [12]. Kemiripan data dapat lebih dari satu, maka dari itu K-NN dapat mengklasifikasi sejumlah data $k$ yang mirip juga data yang memiliki banyak kemiripan. Jarak yang digunakan pada KNN disebut dengan Jarak Euclidien. Selain sederhana dalam mencari jarak terdekat antar data, Kelebihan algoritma ini dapat menggeneralisasi himpunan data training yang relatif kecil [13].

\subsection{Distance}

Jarak atau distance pada sebuah data dilakukan untuk mengukur sebuah kemiripan suatu objek terhadap objek acuannya. Sebelum dilakukan pengelompokkan data untuk di identifikasi, maka terlebih dahulu ditentukan ukuran jarak kedekatannya antar elemen data, salah satu rumus jarak yang sering digunakan pada umumnya yakni menggunakan jarak euclidean (euclidean distance) [14].

\subsection{Fuzzy C-Means}

Algoritma FCM merupakan algoritma klastering yang merupakan teknik untuk menentukan suatu cluster yang optimal. Algoritma ini menganut konsep pendekatan fuzzy sehingga data dapat menjadi anggota dari semua cluster. Nilai matriks keanggotaan terbentuk dengan cara menentukan tingkat keanggotaan dari masing-masing cluster yang ada, yaitu bernilai 0 sampai 1 [4]. Algoritma ini memiliki kelebihan dengan cara penempatan nilai cluster yang tepat daripada metode lainnya. Yaitu dengan memperbaiki pusat cluster secara berulang, maka dapat dilihat bahwa pusat awal cluster bergerak pada lokasi yang tepat [15].

\section{METODOLOGI PENELITIAN}

Penelitian ini menggunakan pendekatan kuantitatif yang bertujuan untuk mencapai sebuah pemahaman. Penelitian kuantitatif umumnya didorong oleh hipotesis yang kemudian dirumuskan dan diuji secara ketat. Aspek dari penelitian kuantitatif yaitu menekankan bahwa pengukuran merupakan suatu dasar untuk memberikan hubungan antara teori, model dan hipotesis. Tujuan dari dibuatnya penelitian ini adalah untuk mendapatkan model prediksi kelulusan tepat waktu dengan menggunakan algoritma FCM-KNN. Maka pada penelitian ini dilakukan dengan mengikuti tahapan seperti Gambar 1.

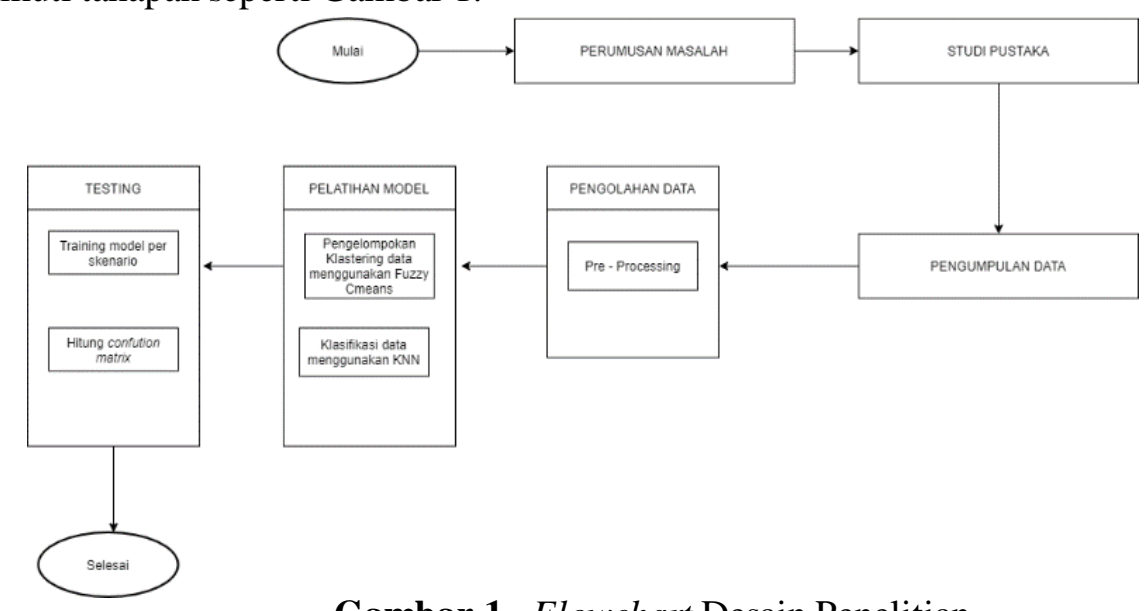

Gambar 1. Flowchart Desain Penelitian

Berikut akan dijelaskan alur dari Flowchart pada Gambar 1.

a. Perumusan Masalah

Pada tahapan ini, masalah yang ada akan menjadi latar belakang yaitu untuk salah satu upaya agar dapat membantu pihak civitas akademik dalam memperbaiki konsep register pada pada 
mahasiswa baru. Dengan menggunakan metode klastering dan klasifikasi menggunakan teknik data mining dalam mengolah kumpulan data mahasiswa yang memungkinkan sistem dapat memprediksi apakah mahasiswa dapat lulus secara tepat waktu atau tidak.

b. Studi Pustaka

Pada tahap ini, penulis melakukan studi pustaka yakni melakukan pemahaman lebih lanjut terhadap metode klastering dan klasifikasi data mining

c. Pengumpulan Data

Pengumpulan data yang digunakan yaitu data mahasiswa UINSA yang terdaftar pada tahun 2014-2015.

d. Pengolahan Data

Pada tahap ini, dilakukan pre-processing data karena masih banyak data yang noisy dari yang diharapkan antara penggunaan nama atau kode. Karena data mentah banyak yang memiliki tipe data kategorik maka akan dirubah ke tipe data numerik. Spesifikasi data dan atribut akan dijelaskan pada Tabel 1 .

Tabel 1. Spesifikasi Atribut Dataset

\begin{tabular}{|c|c|c|c|}
\hline No. & Atribut & Perlakuan & Ekspektasi Hasil \\
\hline 1 & jalur_penerimaan & $\begin{array}{l}\text {-Menghapus data yang tidak valid } \\
\text {-Mengubah variabel kategorikal } \\
\text { menjadi numerik. }\end{array}$ & $\begin{array}{l}\text { Snmptn }=0, \text { Sbmptn }=1, \\
\text { Umptain }=2, \text { Ptain }=3, \\
\text { Mandiri }=4, \text { dst.. }\end{array}$ \\
\hline 2 & kode_prodi & $\begin{array}{l}\text {-Menghapus data yang tidak valid } \\
\text {-Mengubah variabel kategorikal } \\
\text { menjadi numerik }\end{array}$ & $\begin{array}{l}\mathrm{PSI}=0, \mathrm{BKI}=1, \mathrm{SINF}=2, \mathrm{SI} \\
=3, \mathrm{KOM}=4, \mathrm{PAI}=5 \mathrm{AS}= \\
6, \mathrm{PGMI}=7, \mathrm{ES}=8, \mathrm{SKI}= \\
9, \text { dst. }\end{array}$ \\
\hline 3 & pernah_ponpes & -Tidak ada perlakuan & $\begin{array}{l}0=\text { tidak pernah ponpes } \\
1=\text { pernah ponpes }\end{array}$ \\
\hline 4 & asal_smu & $\begin{array}{l}\text {-Menghapus data yang tidak valid } \\
\text {-Mengubah variabel kategorikal } \\
\text { menjadi numerik }\end{array}$ & $\begin{array}{l}\text { Sman }=0, \mathrm{Sma}=1, \mathrm{Smkn}= \\
2, \mathrm{Smk}=3, \mathrm{Man}=4, \mathrm{Ma}= \\
5\end{array}$ \\
\hline 5 & nem_smu & $\begin{array}{l}\text {-Menyamakan rentang nilai dari asal } \\
\text { sekolah } \\
\text { Asal } \\
\text { "SMA,SMAN,MA,MAN" nilai nem } \\
\text { akan dibagi 6 karena jumlah mata } \\
\text { pelajaran saat diujikan ada } 6 \text { jenis. } \\
\text { Asal sekolah "SMK" dan "SMKN" } \\
\text { nilai nem akan dibagi } 4 \text { karena jumlah } \\
\text { mata pelajaran saat diujikan ada } 4 \\
\text { jenis. }\end{array}$ & $\begin{array}{l}\text { Nilai nem SMA } 458.9 \rightarrow \\
76.48 \\
\text { Nilai nem SMK } 314 \rightarrow 78.5\end{array}$ \\
\hline 6 & label kelulusan & $\begin{array}{l}\text {-Mengubah variabel kategorik } \\
\text { menjadi numerik }\end{array}$ & $\begin{array}{l}\text { Lulus }=0 \\
\text { Tidak lulus tepat waktu }=1\end{array}$ \\
\hline
\end{tabular}

Setelah itu dataset akan dilakukan tahap preprocessing data seperti Tabel 2.

Tabel 2. Hasil Setelah Proses Pre-Processing

\begin{tabular}{|c|c|c|c|l|}
\hline jalur_penerimaan & kode_prodi & pernah_ponpes & asal_smu & nem_smu \\
\hline SBMPTN & PSI & 0 & SMK Taruna Surabaya & 32,00 \\
\hline PTAIN & PAI & 0 & MAN Surabaya & 48,05 \\
\hline SBMPTN & PGMI & 0 & MAN Mojosari & 46,60 \\
\hline SNMPTN & KPI & 1 & $\begin{array}{c}\text { SMA Al-Azhar } \\
\text { Menganti }\end{array}$ & 43,30 \\
\hline TES & KPI & 0 & MAN Lamongan & 43,75 \\
\hline
\end{tabular}


e. Pelatihan Model

Setelah data berhasil diolah, maka tahap selanjutnya diperlukan tahap pelatihan model. Langkah-langkah dalam pelatihan model akan dijelaskan dibawah ini.

1. Merancang matriks pada data.

2. Tetapkan jumlah cluster, pangkat, nilai max iterasi, parameter nilai error terkecil dan fungsi objektif awal

3. Menginisialisasi nilai centroid secara random.

4. Hitung nilai pusat cluster. Menggunakan rumus persamaan (1):

$$
V_{k j} \frac{\sum_{i=1}^{n}\left(\left(\mu_{i k}\right) w_{* X_{i j}}\right)}{\sum_{i=1}^{n}\left(\mu_{i k}\right) w}
$$

Keterangan:

$\mathrm{V}_{\mathrm{kj}}$ : nilai $i$ representasi dari pusat cluster, $j$ representasi dari fitur

$\mu_{i k}$ : Nilai derajat keanggotaan pada cluster ke- $i$ dan data ke- $k$

$n$ : banyaknya objek

$m$ : nilai pembobotan (pembobotan $>1$ )

$X_{k j}: k$ representasi dari data dan $j$ representasi dari bobot matriks setiap fitur.

5. Memperbaiki atau update nilai derajat keanggotaan menggunakan rumus persamaan (2).

$$
\mu i k(\text { baru })=\left[\sum_{j=1}^{c}\left(\frac{d_{i k}}{d_{j k}}\right) \frac{2}{m-1}\right]-1
$$

Keterangan:

$\mu_{i k}$ (baru) : nilai $i$ representasi dari cluster dan $k$ representasi dari nilai data terhadap nilai derajat keanggotaan

$d_{i k}$ : nilai $i$ representasi dari cluster dan nilai $k$ representasi dari data terhadap nilai jarak

$d_{j k}$ : nilai $j$ representasi dari cluster lainnya dan nilai $k$ representasi dari data terhadap nilai jarak

$m$ : nilai data.

6. Cek kondisi proses pemberhentian iterasi, jika salah ulangi tahap " 5 " dan jika benar lanjut tahap selanjutnya.

7. Jika terdapat nilai derajat keanggotaan paling besar diantara lainnya, maka menandakan data akan masuk kedalam anggota cluster tersebut.

8. Pemilihan centroid terdekat.

9. Penetapan nilai $\mathrm{K}$ lalu menghitung $\mathrm{K}$ tetangga terdekat terhadap anggota cluster terpilih dilihat dari centroid terdekat, perhitungan nilai antar jarak pusat cluster menggunakan rumus euclidean distance pada persamaan (3).

$$
d_{i} \sqrt{\sum_{i=1}^{p}\left(x_{1}-y_{1}\right)^{2}}
$$

Keterangan:

$\mathrm{x}_{\mathrm{i}}=$ Data uji

$\mathrm{y}_{\mathrm{i}}=$ Data testing

$\mathrm{i}=$ Variabel data

$\mathrm{d}=$ Jarak

$\mathrm{p}=$ Dimensi Data

10. Penentuan kelas pada data testing dengan konsep modus pada data kelas dari $\mathrm{K}$ tetangga. 


\section{f. Testing}

Data yang telah melalui tahap pre-processing digunakan untuk mengevaluasi kinerja sebuah model, dilakukan dengan beberapa skenario pembagian data. Pada tahap ini, digunakan 10fold Cross Validation yang merupakan sebuah metode pengujian data terhadap algoritma dengan membagi sejumlah 10 data dan dibagi kedalam 10 sebuah partisi dengan jumlah yang sama dengan untuk dilakukan evaluasi model algoritma [16]. Cross Validation sering juga digunakan untuk memperkirakan kemampuan suatu generalisasi model dalam suatu metode pembelajaran [17]. Pada proses pengujian digunakan confusion matrix yaitu alat ukur yang memiliki fungsi untuk mengetahui ukuran suatu kinerja atau model algoritma yang telah dibuat. Dari beberapa skenario tersebut bertujuan agar dapat dipilih model dan skenario yang optimal [18]. Sehingga pada proses pelatihan model selanjutnya, hanya dibutuhkan 1 kali pelatihan saja.

\section{PENGUJIAN DAN PEMBAHASAN}

Pada pelatihan model FCM-KNN ini akan menggunakan bahasa pemrograman python dengan tools Jupyter Notebook yang akan dibantu dengan beberapa library dari python yakni scikit learn digunakan untuk membangun model pembelajaran mesin yang didalamnya menyediakan banyak algoritma, library fcmeans gunanya untuk mengimport modul FCM, library pandas untuk membaca file dalam format .csv atau .txt, library numpy untuk mengelola array multi dimensi. Gambar 2 merupakan pseudocode dari tahap FCM.

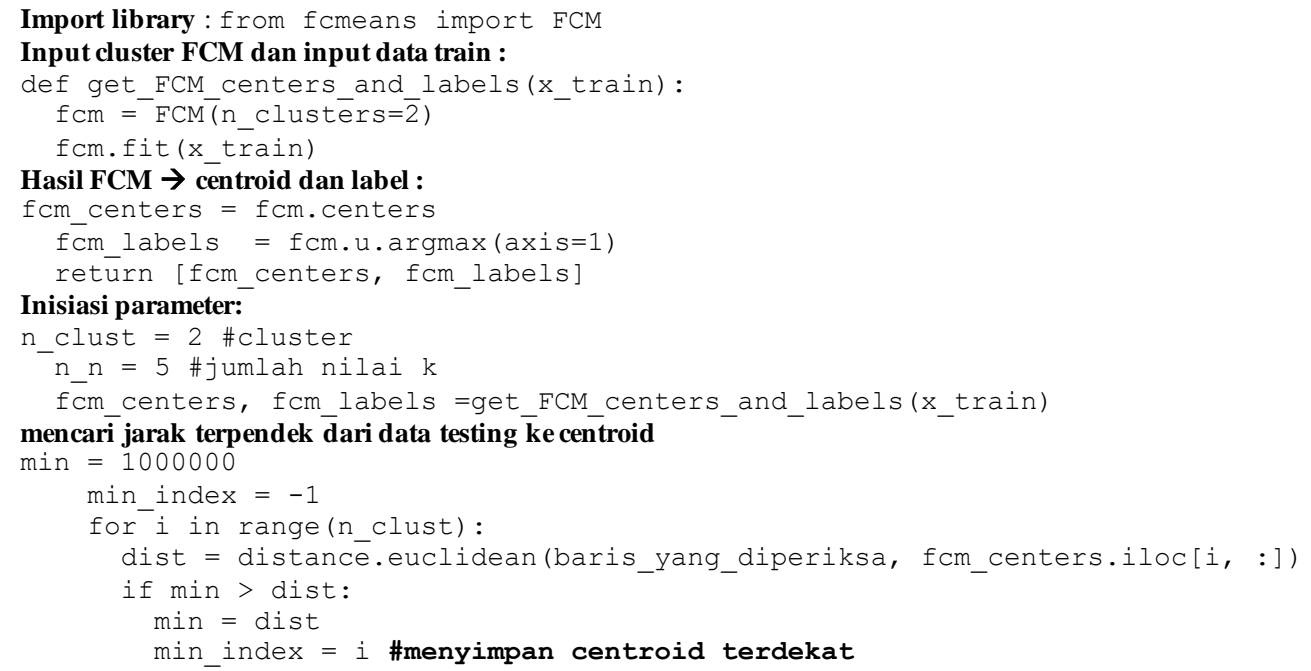

Gambar 2. Pseudocode FCM

Setelah centroid ditemukan maka data akan dikelompokkan berdasarkan anggota cluster nya saja. Disini menggunakan algoritma KNN untuk mencari jarak terdekat antar anggota cluster. Gambar 3 merupakan psuedocode KNN.

Import library :

from sklearn.neighbors import Kneighborsclassifier from scipy.spatial import distance

Ambil indeks data berdasarkan cluster terdekat:

index $x c l u s t=n p$. where $(f \mathrm{~cm}$ labels $==\min$ index)

list_index_xclust $=$ index_xclust $[0]$.tölist ()

mencari tetangga terdekat dari $x$ train dan $y$ train yang sudah diseleksi berdasarkan cluster

$\mathrm{knn}=$ KNeighborsClassifier ( $\mathrm{n}$ neighbors $=\mathrm{n} \mathrm{n}$ )

knn.fit(x_train_new, y_train_new.values.ravel())

Output:

hasil = knn.predict([baris_yang_diperiksa])[0]

predicted $=$ hasil

Gambar 3. Pseudocode KNN 
Penelitian ini merupakan penggabungan antara algoritma Fuzzy C-Means dan K-Nearest Neighbors, dan memiliki jumlah dataset yang cukup banyak, maka untuk pengujian terbaik menurut[19] dalam bukunya yang berjudul "Data Preprocessing in Data Mining" dianjurkan untuk menggunakan teknik validasi 10 -fold cross validation serta dilakukan pengukuran kinerja model dengan skor confusion matrix. Confusion matrix diperoleh dari proses validasi menggunakan teknik 10-fold cross validation, sehingga model yang telah dibuat akan langsung diuji dengan melakukan 10 kali pengujian.

Pengujian dilakukan secara dua kali, yaitu tanpa menggunakan cross validation dan dengan menggunakan cross validation. Berikut merupakan hasil pengujian tanpa menggunakan cross validation akan dipaparkan pada tabel 3.

Tabel 3. Skenario tanpa Cross Validation (train 60\% dan test 40\%)

\begin{tabular}{|l|l|l|}
\hline \multirow{4}{*}{ Cluster 2 } & Skenario k & Accuracy \\
\cline { 2 - 3 } & $\mathrm{k} 1$ & 0.7709 \\
\cline { 2 - 3 } & $\mathrm{k} 3$ & 0.7669 \\
\cline { 2 - 3 } & $\mathrm{k} 5$ & 0.7909 \\
\cline { 2 - 3 } & $\mathrm{k} 7$ & 0.7862 \\
\hline \multirow{5}{*}{ Cluster 3 } & Skenario k & Accuracy \\
\cline { 2 - 3 } & $\mathrm{k} 1$ & 0.7769 \\
\cline { 2 - 3 } & $\mathrm{k} 3$ & 0.7809 \\
\cline { 2 - 3 } & $\mathrm{k} 5$ & 0.8049 \\
\cline { 2 - 3 } & $\mathrm{k} 7$ & 0.8070 \\
\hline \multirow{5}{*}{ Cluster 4 } & Skenario $\mathrm{k}$ & Accuracy \\
\cline { 2 - 3 } & $\mathrm{k} 1$ & 0.7769 \\
\cline { 2 - 3 } & $\mathrm{k} 3$ & 0.7809 \\
\cline { 2 - 3 } & $\mathrm{k} 5$ & 0.8049 \\
\cline { 2 - 3 } & $\mathrm{k} 7$ & 0.8061 \\
\hline
\end{tabular}

Tabel 4. Skenario menggunakan Cross Validation

\begin{tabular}{|c|c|c|}
\hline \multirow{4}{*}{ Cluster 2} & Skenario k & Accuracy \\
\cline { 2 - 3 } & $\mathrm{k} 1$ & 0.6907 \\
\cline { 2 - 3 } & $\mathrm{k} 3$ & 0.6967 \\
\cline { 2 - 3 } & $\mathrm{k} 5$ & 0.7007 \\
\cline { 2 - 3 } Cluster 3 3 & 0.7011 \\
\hline & $\mathrm{k} 7$ & Accuracy \\
\cline { 2 - 3 } & Skenario k & 0.7440 \\
\cline { 2 - 3 } & $\mathrm{k} 3$ & 0.7011 \\
\cline { 2 - 3 } & $\mathrm{k} 5$ & 0.7051 \\
\cline { 2 - 3 } & $\mathrm{k} 7$ & 0.7007 \\
\hline \multirow{4}{*}{ Cluster 4 4} & Accuracy \\
\cline { 2 - 3 } & Skenario k & 0.7435 \\
\cline { 2 - 3 } & $\mathrm{k} 1$ & 0.7131 \\
\cline { 2 - 3 } & $\mathrm{k} 5$ & 0.7107 \\
\cline { 2 - 3 } & $\mathrm{k} 7$ & 0.7119 \\
\hline
\end{tabular}

Dari Tabel 3 dan Tabel 4, dapat diambil kesimpulan bahwa hasil accuracy menggunakan cluster 2, 3 dan 4 dengan model skenario nilai k yang berbeda hasilnya tiap cluster juga memiliki tingkat hasil akurasi yang berbeda pula. Untuk skenario pengujian tanpa menggunakan cross validation didapatkan akurasi tertinggi pada cluster 3 dengan jarak tetangga $\mathrm{k}=7$. Sedangkan skenario pengujian menggunakan cross validation didapatkan akurasi tertinggi pada cluster 3 dan jarak tetangga $\mathrm{k}=1$. Dengan menggunakan skenario nilai $\mathrm{k}$ yang berbeda maka hal ini dapat mempengaruhi tingkat efisiensi pencarian nilai $\mathrm{k}$ (tetangga terdekat) berdasarkan jarak data baru dan tingkat kemiripan data terhadap pola data. Karena pemilihan nilai k menjadi penting karena 
akan mempengaruhi kinerja algoritma. Dari hasil diatas maka selanjutnya akan dihitung menggunakan skor confusion matrix yang akan dijelaskan pada tabel 5

Tabel 5. Confusion Matrix dengan Skenario k=7

\begin{tabular}{|c|c|c|c|}
\hline \multicolumn{2}{|c|}{ Confusion Matrix } & \multicolumn{2}{c|}{ Kelas hasil prediksi } \\
\cline { 3 - 4 } & Positif & Negatif \\
\hline \multirow{2}{*}{ Kelas sebenarnya } & Positif & 72 & 31 \\
\cline { 2 - 4 } & Negatif & 260 & 1139 \\
\hline
\end{tabular}

Dari tabel confusion matrix pada Tabel 5, maka kesimpulannya adalah didapatkan data lulus 72, data lulus yang teridentifikasi tidak lulus 31, data tidak lulus yang teridentifikasi tidak lulus 1139, dan tidak lulus yang teridentifikasi lulus 260 .

\section{KESIMPULAN}

Dari proses penelitian yang telah dilakukan sudah dijelaskan maka dapat disimpulkan:

1. Hasil model prediksi FCM-KNN menggunakan 5 jenis variabel yang selanjutnya dapat digunakan dalam salah satu faktor yang mempengaruhi prediksi kelulusan yakni: jalur penerimaan, jenis program studi, asal smu, pernah ponpes dan nem SMA. Didapatkan hasilnya dengan menggunakan teknik pengujian 10-fold cross validation adalah $\mathrm{k}=1$ dengan menggunakan 3 cluster sedangkan jika menggunakan pengujian training $60 \%$ dan testing 30\% didapatkan hasil 3 cluster dengan $\mathrm{k}=7$.

2. Menggunakan beberapa skenario nilai $\mathrm{k}$ yang berbeda hal ini dapat mempengaruhi tingkat efisiensi pencarian nilai $\mathrm{k}$ (tetangga terdekat) berdasarkan jarak data baru dan tingkat kemiripan data terhadap pola data. Karena pemilihan nilai k menjadi penting karena akan mempengaruhi kinerja algoritma.

3. Performa dari metode FCM-KNN dengan pengujian 10-fold cross validation diperoleh tingkat rata rata akurasinya adalah $71 \%$.

\section{Daftar Pustaka}

[1] A. Saifudin, "Metode Data Mining Untuk Seleksi Calon Mahasiswa Pada Penerimaan Mahasiswa Baru Di Universitas Pamulang," Jurnal Teknologi, vol. 10, no. 1, hlm. 12, 2018.

[2] E. Turban, J. E. Aronson, dan T.-P. Liang, Decision Support Systems and Intelligent, 7 th Ed. 2005.

[3] J. W. G. Putra, Pengenalan Konsep Pembelajaran Mesin dan Deep Learning, 1.3.2020.

[4] R. B. Afrianto dan L. Y. Kurniawati, "Kategorisasi Dokumen Teks Secara Multi Label Menggunakan Fuzzy C-Means Dan K-Nearest Neighbors Pada Artikel Berbahasa Indonesia," JUTI, vol. 11, no. 1, hlm. 23, Jan 2013, doi: 10.12962/j24068535.v11i1.a17.

[5] A. Yusuf, H. Ginardi, dan I. Arieshanti, "Pengembangan Perangkat Lunak Prediktor Nilai Mahasiswa Menggunakan Metode Spectral Clustering dan Bagging Regresi Linier," vol. 1, hlm. 5, 2012.

[6] M. A. Al-Barrak, "Predicting Students Final GPA Using Decision Trees: A Case Study," IJIET, vol. 6, no. 7, hlm. 528-533, 2016, doi: 10.7763/IJIET.2016.V6.745.

[7] M. A. Banjarsari, H. I. Budiman, dan A. Farmadi, "Penerapan K-Optimal Pada Algoritma Knn untuk Prediksi Kelulusan Tepat Waktu Mahasiswa Program Studi Ilmu Komputer Fmipa Unlam Berdasarkan IP Sampai Dengan Semester 4,”vol. 02, hlm. 15, 2015.

[8] A. Maulana dan A. A. Fajrin, "Penerapan Data Mining Untuk Analisis Pola Pembelian Konsumen Dengan Algoritma Fp-Growth Pada Data Transaksi Penjualan Spare Part Motor," Klik - Kumpulan Jurnal Ilmu Komputer, vol. 5, no. 1, hlm. 27-36, Feb 2018, doi: 10.20527/klik.v5i1.100. 
[9] Aradea, A. Satriyo, Z. Ariyan, dan A. Yuliana, "Penerapan Decision Tree Untuk Penentuan Pola Data Penerimaan Mahasiswa Baru," hlm. 7, 2011.

[10] F. Fansuri, “Jurnal Komputer dan Informatika (KOMPUTA)," vol. 1, hlm. 7, 2012.

[11] C. Darujati dan A. B. Gumelar, "Pemanfaatan Teknik Supervised Untuk Klasifikasi Teks Bahasa Indonesia," hlm. 9, 2012.

[12] N. Mariana, R. S. Redjeki, dan J. A. Razaq, "Penerapan Algoritma K-NN (Nearest Neighbor) Untuk Deteksi Penyakit (Kanker Serviks)," vol. Vol. 7 No.1, Mar 2015.

[13] R. H. D. Satriya dan E. Santoso, "Implementasi Metode Ensemble K-Nearest Neighbor untuk Prediksi Nilai Tukar Rupiah Terhadap Dollar Amerika," hlm. 8, 2018.

[14] D. Nugraheny, "Metode Nilai Jarak Guna Kesamaan Atau Kemiripan Ciri Suatu Citra (Kasus Deteksi Awan Cumulonimbus Menggunakan Principal Component Analysis)," Angkasa, vol. 7, no. 2, hlm. 21, Sep 2017, doi: 10.28989/angkasa.v7i2.145.

[15] F. Agustini, "Implementasi Algoritma Fuzzy C-Means Studi Kasus Penjualan Di Sushigroove Restaurant," vol. 3, no. 1, hlm. 6, 2017.

[16] P. Pitria, "Analisis Sentimen Pengguna Twitter Pada Akun Resmi Samsung Indonesia Dengan Menggunakan Naïve Bayes," hlm. 8, 2014.

[17] A. A. Mahran, R. K. Hapsari, dan H. Nugroho, "Penerapan Naive Bayes Gaussian Pada Klasifikasi Jenis Jamur Berdasarkan Ciri Statistik Orde Pertama,” vol. Vol 5. No 2, 2020.

[18] J. Han, "Data Mining: Concepts and Techniques," hlm. 128, 2011.

[19] S. García, J. Luengo, dan F. Herrera, Data Preprocessing in Data Mining, vol. 72. 2015. 